\title{
A POÉTICA SURREALISTA-BARROCA DE MARIA MARTINS E A AMAZÔNIA
}

\section{THE SURREALIST-BAROQUE POETIC OF MARIA MARTINS AND THE AMAZON}

\author{
Rita Lenira de Freitas Bittencourt ${ }^{1}$ \\ uma mulher não gostava de dizer \\ "uma mulher" \\ o que ouvia era "mamu” \\ também não gostava \\ de dizer "uma amiga" \\ "mami" \\ e ainda outra mulher havia \\ que não gostava de "mamão" \\ nem de "mamoa" \\ e muito menos de "mamona"
} Angélica Freitas, um útero é do tamanho de um punho.

\begin{abstract}
RESUMO: Este ensaio tem como objetivo abordar as imagens da Amazônia na curiosa obra da escultora e escritora Maria Martins (1894-1973), uma das poucas mulheres artistas brasileiras a ser reconhecida internacionalmente em sua época. Este ensaio examina uma pequena parte de sua obra artística - três esculturas, dois poemas e uma gravura -, elaborada no contexto da vanguarda europeia e americana, em diálogo com o modernismo antropofágico brasileiro. Segue a hipótese geral de que as apropriações culturais de Maria têm conexões, ao mesmo tempo, com o movimento surrealista, com a arte barroca da América Latina e com os estudos teóricos contemporâneos, reorganizando categorias como centro e margens e renovando e enriquecendo as reflexões sobre os espaços simbólicos na literatura e nas artes.
\end{abstract}

PALAVRAS-CHAVE: Arte moderna; visualidade; deslocamentos; poética da Amazônia.

ABSTRACT: This essay aims to address the images of the Amazon in the curious work of sculptor and writer Maria Martins (1894-1973), one of the few Brazilian women artists to be recognized internationally in her time. This paper examines a small part of her artistic work - three sculptures, two poems and an engraving - elaborated in the context of the European and American avant-garde, drawing a parallel with the Brazilian anthropophagic modernist movement. We follow the general hypothesis that Maria's cultural appropriations have connections, at the same time, with the surrealist movement,

\footnotetext{
${ }^{1}$ Doutora em Literatura pela UFSC, com estágio pós-doutoral no Centro de Estudos Comparatistas da Faculdade de Letras da Universidade de Lisboa (CECFLUL). Professora da UFRGS e docente do PPG em Letras.
} 
with the Baroque art of Latin America and with contemporary theoretical studies, reorganizing concepts such as center and margins, as well as renewing and enriching researches on symbolic spaces in literature and the arts.

KEYWORDS: Modern art; visuality; displacements; poetics of the Amazon.

Este breve ensaio se ocupa de algumas obras de Maria Martins, que envolvem uma leitura artística da Amazônia, em formas e temáticas capazes de recriar a espacialidade e o instigante imaginário da região, valendo-se de diálogos com outras referências conhecidas, literárias e visuais, e de um interesse genuíno pelas imagens, sonhos, luzes e sombras de um cenário que, desde sempre, atrai escritores, artistas e poetas.

Maria Martins, escultora, desenhista, escritora, vem se tornando, mais recentemente, uma referência obrigatória: Recebeu uma sala especial na Exposição dos Surrealistas no Centro Cultural do Banco do Brasil, RJ, em 2001; mereceu uma biografia, Maria, em 2004, escrita por Ana Arruda Callado; figurou, com Marcel Duchamp, no tratado de Raul Antelo Maria con Marcel, em 2006, Buenos Aires, e na versão em português, 2010; foi estrela, em 2013, da exposição individual Maria Martins: Metamorfoses, na Grande Sala do MAM, em São Paulo, com curadoria de Veronica Stigger, só para citar alguns eventos importantes.

A artista atravessou o século XX, cronológica e artisticamente, juntando arte e vida, linguagem e corpo, e, por sua performance que alia uma mentalidade contraditória a uma habilidade ímpar de circular entre centro e periferias implodindo as hierarquias, garantiu um espaço de produção de mulheres em meios profundamente misóginos. É reconhecida tardiamente no Brasil, na deriva do pensamento moderno, frequentemente associada aos surrealistas, entre outros motivos, por ter empolgado, com seus poemas em prosa, a André Breton (1896-1966).

Efetivamente, suas opções estéticas ultrapassaram as dos surrealistas, ao fugir dos parâmetros restritivos de suas pautas e ao estabelecer relações temáticas e formais com o fantástico e o maravilhoso latino americanos, o que a levou a experimentar, em deslocamento, uma espécie de barroquismo tropical, que se tornaria uma linha de força importante em seus trabalhos.

Depois de muitos anos residindo no exterior, Maria retornou ao Brasil na década de 1940, quando foi uma das idealizadoras e também exibiu alguns dos seus trabalhos na 
Primeira Bienal de Arte Moderna de São Paulo, que aconteceu em 1951. Ao inserir-se nos meios artísticos locais, contribuiu para a redefinição das implicações entre arte e gênero, e, por suas incursões no imaginário brasileiro para além do figurativismo, propiciou leituras heterotópicas que desafiaram as convenções artísticas vigentes.

Escolhi a cena múltipla do poema em epígrafe, de mulheres e seus gostos, os sons em fuga do materno, maternal, misógino, meloso, místico; de mudez e de medo, escaneados, por Angélica Freitas, em invenção contra-discursiva de outros "m": "mulher", "mamu", “amiga", "mami”, "mamão", "mamoa”, "mamona", retirado do controverso e genialmente polêmico livrinho um útero é do tamanho de um punho, para abrir este ensaio e situar a artista brasileira, assim como para retornar e repensar brevemente sobre a atuação e o lugar, na história da literatura e das artes, de uma "mulhermamoa", uma "mulher-mamona", fruto estranho ${ }^{2}$ e ao mesmo tempo fundador, fundamental, no período brasileiro denominado modernismo.

\section{A artista}

Maria de Lourdes Faria Alves nasceu em 1894, na pequena Campanha da Princesa, em Minas Gerais, e morreu em 1973, no Rio de Janeiro, com 78 anos e cercada por uma aura de admiração e reconhecimento. Afilhada de Euclides da Cunha, nascida em família abastada, branca e letrada, acompanhou as "querelas" artísticas nacionais e internacionais, para falar com Carlos Zilio ${ }^{3}$, produzindo suas obras em interlocução, por vezes tensa, com o fim do século XIX e com as transformações reivindicadas pelo modernismo de 22 e pelas vanguardas europeias.

\footnotetext{
${ }^{2}$ A teórica e professora Florência Garramuño, em seu livro Frutos Estranhos (2014), e no que organizou em parceria com Ana Kiffer, Expansões contemporâneas (2014), atribui ao literário em campo expandido as marcas da inespecificidade, explorando as configurações heterocrônicas e compartilhando-as com as outras formas - artísticas ou nem tanto -, em convivência fértil e incontornável. Nesses trabalhos, há também um direcionamento às afecções, ao irrepetível das aproximações inusitadas e não programadas, que é da ordem do crítico-poético e que tento explorar neste ensaio.

${ }^{3}$ Pensando os alicerces conceituais do modernismo brasileiro, tendo a questão da nossa identidade cultural como tema, afirma o teórico de A Querela do Brasil: "Entre as diversas propostas que este movimento trouxe para a arte brasileira, a principal foi a de lhe dar uma identidade própria. Embora esta intenção não fosse inédita na nossa arte, há pela primeira vez um sentido coletivo envolvendo o conjunto da produção de arte mais importante de uma época reunida através de ações comuns e programas teóricos" (ZILIO, 1997, p.16) Apesar de diferenças individuais entre os artistas, o modernismo vai de uma fase inicial, tributária das vanguardas europeias até um momento realista e temático, onde se situa, por exemplo, Portinari, e segue em direção ao impressionismo, explorando menos "o que" pintar ou esculpir e mais "o como", pensando meios e formas e iniciando o abandono da representação.
} 
A artista conhece o diplomata gaúcho Carlos Martins Pereira e Souza (18841965), em 1920, durante um evento em que o casal real da Bélgica é recebido em Belo Horizonte. Carlos, alguns anos depois, será seu segundo marido, após uma separação tumultuada do primeiro esposo, quando Maria viaja para a Europa e passa a residir em Paris. Com Martins, já embaixatriz, Maria, enquanto investe em sua formação, residirá em vários países, até se estabelecer nos EUA, onde fará sua primeira exposição individual, em Washington, 1941, cujo catálogo traz na capa um desenho de Cândido Portinari (1903-1962). As obras, em sua maioria, são esculturas em madeira, terracota e gesso. Ela exibe apenas três bronzes, ainda bastante figurativos. Mesmo assim, a escultura Salomé, em sua primeira versão, vai chamar a atenção e sofrerá diferentes releituras e atualizações, até o erotismo crítico de $O$ sétimo véu, de 1948, um dos seus trabalhos mais conhecidos. De Carlos, a artista adotará o sobrenome artístico - Martins -, mas essa primeira exposição traz como título apenas Maria.

Em 1943, em Nova York, a artista lança um livro ${ }^{4}$, Amazônia, com uma versão de poemas em prosa das lendas que surgem em esculturas exibidas na exposição Maria: New Sculptures que ela divide com Piet Mondrian (1872-1944), que reside nos Estados Unidos desde 1940 (Mondrian: New Paintings). O famoso quadro do pintor holandês Broadway Boogie-Woogie, completado no ano da exposição, foi comprado por cerca de 800 dólares por Maria Martins, que mais tarde o doou ao Museu de Arte Moderna de Nova York.

Já então se comentava a respeito do romance de Maria Martins com Marcel Duchamp (1887-1968), artista conceitual que, também, como Mondrian, foge da guerra na Europa e reside, por longas temporadas, nos Estados Unidos. A relação erótica entre Maria e Marcel acabará por conformar muitas das leituras - ou das não leituras - do trabalho da escultora. Sem dúvida, a parceria entre ambos foi intensa e propiciou inúmeras trocas intelectuais e formais. Maria, várias vezes, participa como modelo das obras de Duchamp e esses trabalhos ficaram registrados nas coleções e no anedotário da história da arte moderna ${ }^{5}$.

\footnotetext{
${ }^{4}$ Segundo a pesquisadora Larissa Costa da Mata, no artigo "Da Amazônia, de Maria Martins" (2013), "Os poemas em prosa de Amazônia pertencem ao catálogo publicado em uma tiragem de 100 exemplares para a exposição "Maria: Novas Esculturas" (...)em 1943, em Nova Iorque. O catálogo originalmente contou com a apresentação de Jorge Zarur, do Instituto Histórico e Geográfico Brasileiro, e se compunha das imagens das esculturas e de oito poemas em prosa e em língua inglesa correspondentes a essas obras Amazônia, Iara, Aiocá, Iaci, Boiúna, Cobra Grande, Boto e Iemanjá." No trabalho de Mata também consta uma cópia fotográfica da capa do catálogo e os oito poemas em prosa, no original em inglês e em tradução para o português. Ver http://sibila.com.br/poemas/da-amazonia-de-maria-martins/9914

5 É o caso de Priére de Toucher (Tocar, por favor), de Duchamp, em forma de seio de material emborrachado, corante e veludo, que consta na capa da segunda exposição internacional Le Surréalisme, realizada em 1947, em Paris, apresentada por Breton e Duchamp. E também a famosa Etant donnés: 1. La
} 
Na biografia de Maria Martins, escrita por Ana Arruda Callado e publicada em 2004, no texto de abertura, datado “Agosto de 2001", que descreve uma visita à exposição Surrealistas no Centro Cultural do Banco do Brasil, no RJ, a autora faz uma pergunta central, que também atravessa este ensaio:

\begin{abstract}
Percorro vagarosamente os três andares repletos de quadros, gravuras, desenhos e esculturas interessantes, alguns excelentes, todos de renomados mestres das artes plásticas. Mas, em uma sala especial, minha emoção é tocada fortemente. É a de Maria Martins, ali apresentada por 18 esculturas e, nas paredes, algumas de suas poesias em francês, que haviam sido gravadas em metal e lançadas em álbum em Nova York, em 1946. Aquela sala vale toda a exposição, sinto imediatamente. E depois de ver, mirar, admirar cada uma daquelas peças, uma indignação me ocorre e me dá uma sensação de revolta: por que, até aquele momento mágico, só ouvira falar de Maria como embaixatriz ou amante de Marcel Duchamp? (Callado, 2004, p.1)
\end{abstract}

Ainda que a pergunta se autorresponda - as vozes que falam da artista e que a tentam definir dizem mais do seu segundo marido e de seu amante. $\mathrm{O}$ primeiro, diplomata do governo de Getúlio Vargas em Washington e, posteriormente, representante do Brasil na ONU, no governo Gaspar Dutra; o segundo, um dos artistas mais conhecidos do século XX, cuja obra é demais conhecida, dos ready-mades ao Grande Vidro, das Notas ao ultrassecreto Dados, montado em segredo por mais de 20 anos e do qual Maria participou. Por isso, de alguma forma, a figura da artista viveu à sombra desses homens, em parte ofuscada por eles.

Afora isso, a personalidade inquieta e libertária de Maria, afrontando os padrões estéticos, tanto das vanguardas cubistas quanto das surrealistas, além dos padrões morais de uma burguesia nacional tacanha, contribuíram para a recepção tardia de sua obra no Brasil. Vale destacar que, junto com Maria, na primeira Bienal de São Paulo, em 1951, também estava Tarsila do Amaral (1886-1973), musa e mentora do modernismo antropofágico, que sofreu, igualmente, uma espécie de obnubilamento pela figura carismática e potente de seu então marido, Oswald de Andrade.

No tratado Maria com Marcel: Duchamp nos trópicos $(2010)^{6}$, o pesquisador Raul Antelo resgata o papel importante de Maria Martins, tanto em relação à cena local das artes plásticas quanto no modernismo internacional, quando equaciona o tanto, em

chute d'eau. 2. Le gaz d'éclairage (Dados: 1. A Queda de água, 2. O gás de iluminação), iniciada em 1944 e só dada por concluída na década de 1960. Em ambos, Maria Martins foi modelo. Há vários outros desenhos e moldes, esculturas menores, que também tiveram a participação da artista brasileira.

${ }^{6} \mathrm{O}$ livro Maria com Marcel: Duchamp nos trópicos, de Raul Antelo, ainda que tenha sido escrito em português, foi publicado inicialmente em espanhol, 2006, em Buenos Aires, pela Siglo XXI. Em 2010, sai pela Editora da UFMG, em Belo Horizonte, a que teria sido a versão original, segundo Maria Salete Borba (2012, p.290): "poucos sabem que Maria com Marcel foi escrito em português, e que a versão em espanhol é uma tradução do professor argentino Mário Câmara...". Para este ensaio, consultei e citei partes de ambas as edições. 
Duchamp, do legado acefálico e tropical de Maria, numa via de mão dupla, mais colaborativa e menos hierarquizada. Antelo abre o capítulo "3. O impossível”, com uma declaração de Nora Martins, filha da artista, da qual cito um pequeno trecho:

\begin{abstract}
Minha mãe, Maria, foi muitas pessoas na verdade. Para começar, ela era muito bonita, o que ajuda, e era uma escultora, uma artista, uma excelente embaixatriz, uma poeta, uma escritora, e foi extremamente interessada em tudo. Era curiosa. Queria aprender. Costumava dizer que o dia em que você para de aprender, você morre. Foi uma pessoa complexa e cheia de charme. (Antelo, 2010, p.117)
\end{abstract}

Sua vida cosmopolita de embaixatriz, aliada a uma personalidade aberta à mobilidade fará com que Maria venha a escrever um relato de viagem sobre a Índia, por exemplo, e também outros volumes sobre religiosidade asiática e sobre a China; ou que monte um projeto de biografias, do qual chegou a escrever apenas um volume, dedicado a Nietszche, que lhe valeu ainda mais atitudes de rejeição no Brasil.

Neste ensaio, o que me interessa é atravessar os campos das artes visuais, da literatura e da cultura brasileiras, observando as obras plásticas de Maria Martins, a respeito do imaginário espacial amazônico, e os poemas em prosa, que apresentam figuras mitológicas e lendárias de um ponto de vista pessoal, entre o misticismo e a antropologia, que acabam por levar, enfim, às reflexões escultóricas sobre a condição das mulheres artistas. Montei um recorte desses trabalhos, passando brevemente por eles, inventando uma leitura que talvez possa ser estendida ao conjunto e faça jus aos múltiplos fazeres da artista.

\title{
Amazônia e Maria Martins
}

Na exposição de 1941, na Corcoran Galery, em Washington, a escultura Iara foi apresentada em gesso. Recebe uma versão em bronze, exibida em 1943, na Valentine Gallery de Nova York, sendo adquirida pelo Philadelphia Museum of Art. Alimentando o imaginário romanesco da relação da escultora com Duchamp, conta-se que o artista francês exigiu que sua famosa obra Grande Vidro, quando transferida ao mesmo Museu, fosse posicionada de modo a dar vista direto à saída ao jardim, onde estaria a Iara, de Maria Martins. Assim, novamente, as relações de espelhamento ultrapassam o erotismo 
de uma troca de casal e dão a ver um palimpsesto temporal, a partir da espacialidade posta em cena, que aponta para um projeto duradouro e colaborativo entre ambos ${ }^{7}$.

O conjunto de trabalhos da exposição de 1943, num total de oito, recebe o título de Amazônia. Conforme já mencionado na nota 2, o catálogo da exposição é um livro de poemas em prosa, escrito em inglês, a respeito do espaço e das lendas do norte brasileiro e do Caribe, revisitados pelas esculturas: Amazônia, Iara, Aiocá, Iaci, Boiúna, Cobra Grande, Boto e Iemanjá.

Afora a materialização em gesso e em bronze, Raul Antelo, em Maria con Marcel (2006), exibe também uma gravura, com o mesmo título, de 1940, o que comprova o interesse múltiplo da autora tanto por esta figura lendária, quanto pela poética caribenho/amazônica, que envolve sedução e violência, captada em suportes diversos:

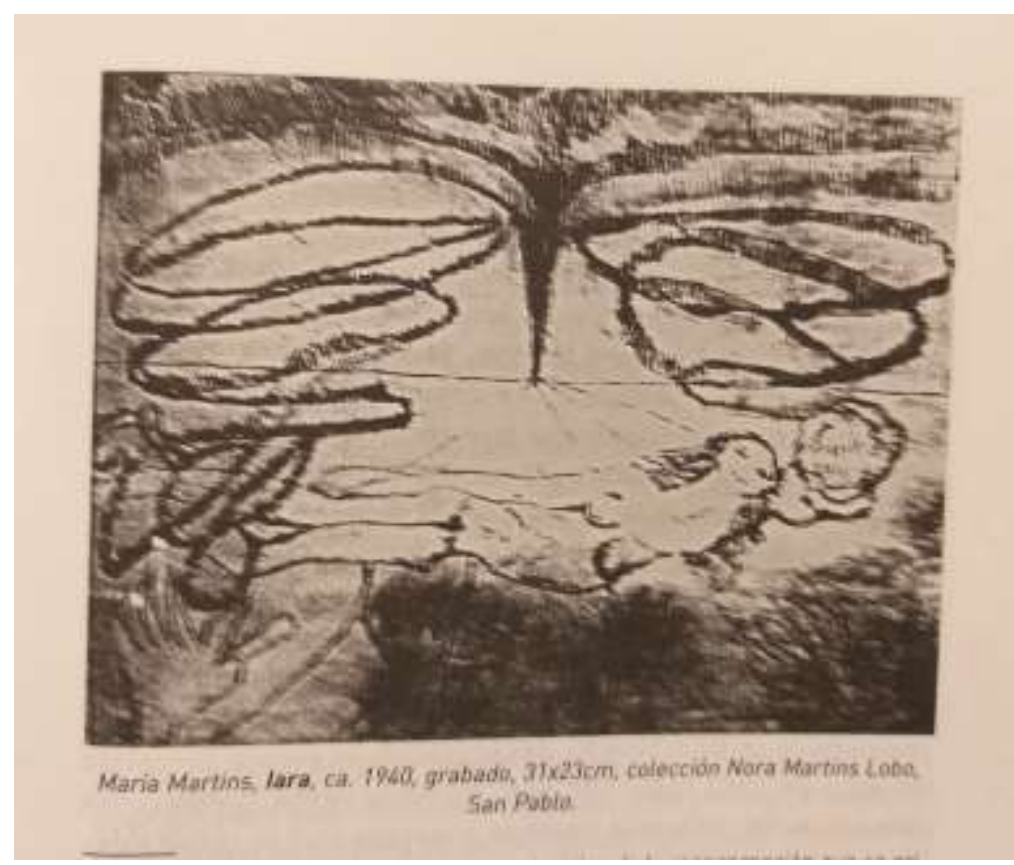

Fig.1. Iara. Maria Martins. Reprodução fotográfica inserida no Cap. "Lo imposible", p.151, de Antelo (2006).

A versão do poema em prosa de Maria Martins, traduzido para o português, é a seguinte:

\footnotetext{
${ }^{7}$ Larissa da Costa Mata, no artigo "Da Amazônia, de Maria Martins" (2013), comenta em nota: "Segundo Raúl Antelo em Maria com Marcel (2010), o pedido de posicionar a escultura da amante no jardim do museu fez parte de um projeto de "hiperdimensionalidade" de Duchamp, por meio do qual a obra de Maria Martins se tornaria um hipertexto da pintura do amante, em que tempo e espaço se fundiriam pelo reflexo que marca o tempo presente do espectador no vidro. Para o autor, essa fusão teria como resultado um presente de vários tempos simultâneos". Hoje este arranjo foi desfeito, pois a Iara de Maria Martins já não está lá.
} 


\section{Iara}

Iara está apaixonada pelo amor.

Ela é a sereia do Amazonas.

Não importa o quão distante o amor esteja, Iara canta o seu canto de sedução. Embora perdido de amor por uma mortal, o amante ouve a canção e escuta Iara. Ai dele se a escuta duas vezes! Ele é conduzido, então, a buscá-la.

Ele a procura. Lá está ela: em pé à frente do Rio imenso, sobre uma Vitória Régia, o lótus carmim do Amazonas. Ela é tão branca que reluz o reflexo verde das folhas. Os seus olhos de esmeralda carregam a transparência e a perfídia das águas. O seu cabelo loiro-esverdeado a envolve com uma sedução diferente.

Ele não pode resistir - escutou bem demais o canto de tentação de Iara.

Iara oferece-lhe uma flor e o beijo da morte. Ele desaparece com ela no riacho. Seguem juntos o curso das águas - um caminho ora calmo, ora tempestuoso até o momento em que surge um novo amor, não importa onde no mundo imenso, e Iara retorna e aniquila outro mortal que não consegue resistir à tentação da assassina - Iara. (Mata, 2013, s/p)

É evidente, no poema, o diálogo de Maria Martins com a temática, as cores e a espacialidade exploradas pelo modernismo antropofágico, seja na rapsódia Macunaíma, o herói sem nenhum caráter, de Mario de Andrade, de 1928, seja nas conhecidas pinturas de Tarsila do Amaral, como Floresta, de 1925, ou O ovo (Urutu) de 1928, ou mesmo $O$ Abaporu, do mesmo ano, certamente a mais emblemática de todas, tornada ícone do movimento. Também se relaciona explicitamente à concepção do erotismo na arte de Raul Bopp, que, no longo poema Cobra Norato, igualmente de 1928, explora um patrimônio de mitos e lendas populares, e monta uma face, digamos, "bárbara", não civilizada, da cultura nacional, conjugada a um saber erudito retirado das notas etnográficas, dos cantos tupis e da psicanálise ${ }^{8}$.

\footnotetext{
${ }^{8}$ A cena do primeiro modernismo brasileiro e algumas de suas conexões com a américa Latina, em suas relações ao mesmo tempo próximas e distantes da região amazônica, foi explorada no meu livro Guerra e Poesia. Dispositivos bélico-poéticos do Modernismo (BITTECOURTT, 2014), especialmente no capítulo 5, que estuda os dispositivos ativados em uma guerra simbólica, de apreensão e posse do espaço nacional, em si mesma equívoca e ambivalente. Também, na parte 6. "Antologia da guerra", as pinturas e poemas mencionados neste ensaio, figuram numa combinação heterogênea, onde consta, inclusive, em espanhol, o mito "La gran serpiente" atribuído ao povo mosetene, do norte da Bolívia, recolhido pelo pintor, inventor e escritor argentino Xul Solar, e que, aqui, será uma das escolhas escultóricas de Maria Martins. Um desdobramento desta problemática foi desenvolvida na conferência "A Poesia e o Local: Tensões Modernistas”, apresentada no I Simpósio de Estudos da Linguagem, SIEL AMAZÔNIA, na UNIFESSPA, Marabá, PA, em 2019, e adaptada, posteriormente, no ensaio "Tensões Modernistas em Mário de Andrade, Tarsila do Amaral e Raul Bopp", publicado na VIS. Revista do Programa de Pós-graduação em Artes Visuais da UnB. V.18, número 2, 2019 , pp. 212-227.
} 
Incorporando, ainda, uma dimensão lírica e amorosa aliada ao movimento, um traço distintivo nos trabalhos de Tarsila e Bopp é a abertura a uma deliberada ingenuidade, a uma espécie de fantasia de origem que circula no que se denominou "primitivismo". Se Maria Martins, alguns anos depois, dialoga, também, com essa tradição, será para deslocar a valoração ao plano oposto, potencializando o estranhamento, ou seja, para dar uma vazão ainda mais desbordada ao irracional e explorar a potência erótica e destruidora como sustentáculos de sua arte. Segundo Bopp, uma das teses discutidas pelos "novos antropófagos" brasileiros, tendo em vista a organização do "Primeiro Congresso Mundial de Antropofagia" - evento jamais realizado - era a da libido nacional:

Outra tese seria sobre a libido brasileira (Histórias do sexo cifrado). Constaria de um estudo fundamentado sobre a época de Freud e do Boto (Boto, uma espécie de Dom João da Amazônia)

- Quem foi?

- Foi o boto. Imunizou o artigo 266 do Código Penal.

Há árvores com atributos mágicos. Moça tece filho sem conhecer homem.

- Curumim, quem é teu pai?

- Eu sou filho do taperebá.

Curandeiro na lua nova fica espiando a orgia do mato. Apropria-se das virtudes das plantas. Colhe ervas de destorcer quebranto.

Prepara puçangas de seduções femininas. Amuletos com força de sortilégio. Ficam almas sequestradas pela bruxaria (Bopp, 1975, p.90)

O "sexo cifrado", que poderia ser a cifra do recalque, assinala, aqui, uma espécie de erotização generalizada, expandida aos animais e às plantas, transmutada à vivência cotidiana. que é partilhada com a magia e o mistério, e que vai marcar, mais ainda, os poemas em prosa de Maria Martins. O que dá título à sua exposição de 1943, ao invocar as forças totêmicas da cultura em um "casamento primordial" mito de origem do lugar, resgata uma tradição ao mesmo tempo conhecida e exótica, parente das narrativas sacrificiais, unindo e separando os ditos "Velho" e "Novo" Mundo. Com isso, Maria aproxima-se, por um lado, das vanguardas europeias, e, por outro, cita explicitamente a cobra grande, personagem de Xul Solar, conforme a nota 7, e de Raul Bopp. Eis o poema de Maria Martins, em tradução ao português:

\section{Amazônia}

Todos os anos, para que a floresta possa prosperar com toda a sua força e exuberante beleza, o Rio deve se unir à Terra. Este casamento se realiza graças ao encontro de uma mulher com uma serpente.

A serpente parte das profundezas do riacho e segue à procura da sonhada mulher. 
Dia e noite, ondulando-se através da selva, partindo as robustas cordas das trepadeiras, emaranhando-se nos seus laços tortuosos, derrotando os animais, enlouquecendo os pássaros, desliza pela floresta, até encontrar a mulher escolhida.

Ela sempre é a mais bela entre as belas morenas do crepúsculo dourado dessas matas. Cobra Norato a tornará a Rainha do Amazonas.

Ela se veste com os seus trajes mais finos, se enfeita com as suas joias mais raras e se entrega ao sacrifício, desvairada de amor e medo.

Agora a floresta viverá por mais um ano, mais forte, mais misteriosa, mais brilhante e mais sombria, guardando no interior do seu seio virgem as secretas riquezas cobiçadas pelos homens. (Mata, 2013, s/p)

A recepção entusiástica ao trabalho da artista brasileira na cena norte-americana, ainda, segundo Mata, está intimamente ligada ao desencanto do período simultâneo e posterior à segunda guerra mundial, quando os exilados europeus, desencantados com os projetos civilizatórios do século XX, circulavam pelas Américas, o que, afora o talento evidente da escultora, justifica em parte o impacto das obras e do seu projeto:

\begin{abstract}
André Breton lhe dedicara um ensaio por ocasião da sua primeira exposição individual na galeria Julien Lévy de Nova Iorque em 1947. Nesse texto, o autor destaca a proximidade da obra de Maria com a natureza tropical, bem como o fato de recorrer às forças vitais como contraponto aos sistemas políticos embrutecidos e baseados em uma razão incipiente. As esculturas de Maria Martins assumiriam o ritmo flexível da natureza, "as ondas da terra", para transmutar a estagnação política com o princípio telúrico, presente também no seu interesse pela mitologia amazônica. (Mata, 2013, s/p)
\end{abstract}

Assim, a pesquisadora insere Maria Martins em uma cena ampla, citando diretamente o teórico e artista surrealista escrevendo sobre a exposição de Maria Martins e dando destaque a seu lugar ex-ótico, que se joga para fora de tempos e espaços, refugiando-se menos no místico, e mais no corpóreo. Escreve Breton:

É o perpétuo recurso às fontes vitais da natureza (do espírito assim como do corpo) que ela se impunha, é a sua constante preocupação de colocar o psicológico sobre o cosmológico, opondo-se à tendência contrária geralmente predominante que leva a humanidade a uma via de sofismas cada vez mais perigosa (Breton apud Mata, 2013, s/p)

Dentre as obras que compõem a série Amazônia, vale citar a escultura Cobra Grande, de 1943. Em bronze, um trabalho que associa o mineral ao orgânico, o maquínico ao botânico, ultrapassando em parte os limites estéticos da antropofagia oswaldiana e, simultaneamente alimentando-se deles, como em sacrifício ou ritual, quando o corpo retorcido parece ligar-se ao conjunto vegetal, num circuito de retroalimentação infinita: 


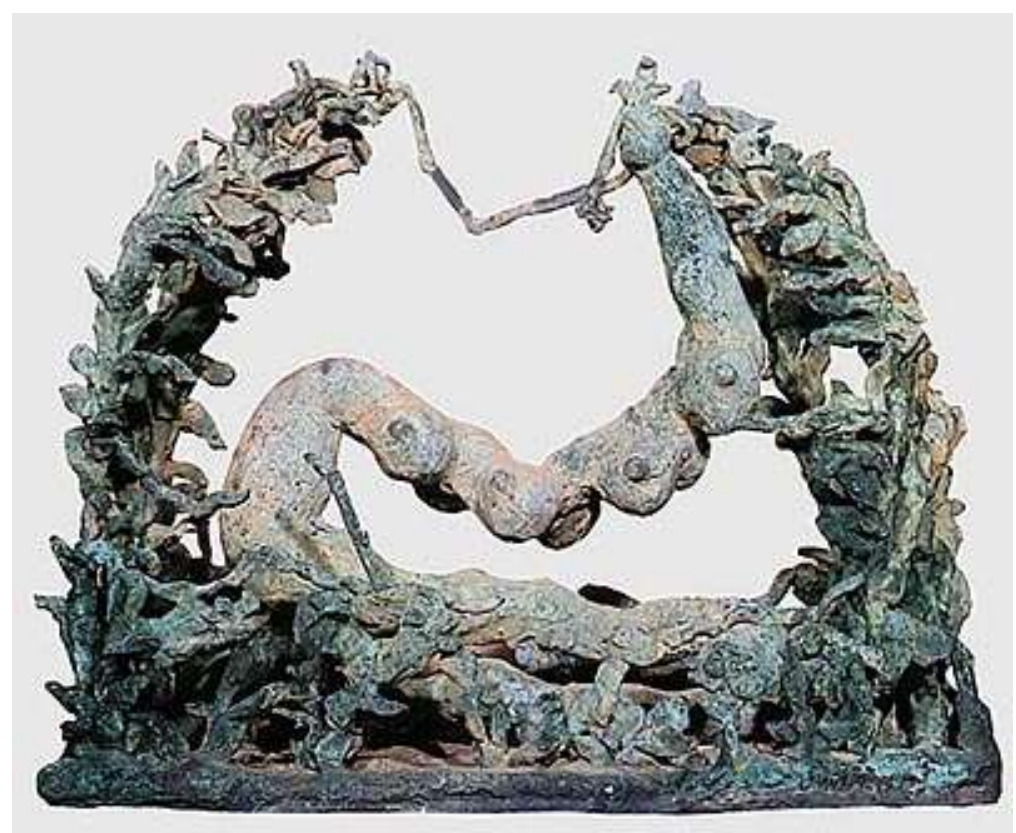

Fig. 2. Cobra grande. Maria Martins. Reprodução fotográfica Daniel Couri

Se havia um interesse comum entre Tarsila, Bopp, Mário de Andrade e Oswald de Andrade, dentre outros, em torno da apreensão da nacionalidade, em mote incorporador da carga antropológica colonial, talvez, como uma de suas marcas discursivas e singulares, resultante, já, de uma trajetória reflexiva e pictórica, Maria Martins tenha percebido essas e outras questões a desafiarem a arte, explorando-as estreitamente ligadas à acefalidade e à performance. Por isso, a conjugação barroquizante dos contrastes, a monumentalidade discreta de seus arranjos e a variedade de interesses que a fazem circular pela filosofia e pela geografia, por tradições diversas e corpos mutantes, de forma tão provocadora que atrai leituras superficiais e até machistas.

Maria Salete Borba, ao comentar o trabalho de Antelo, que vem reverter as críticas do alto modernismo, também compartilha desta postura: "Antelo rearma a leitura e lê Maria Martins apontando justamente o que é ignorado (...), ou seja, a erudição, os contatos que além de brilho e grandiosidade dão consistência ao trabalho da escultora." (Borba, 2012, p.293) E, mais adiante, retornando ao mote proposto por Callado, na primeira parte deste ensaio, a pesquisadora acrescenta, a respeito do autor de Maria com Marcel: "[ele, Antelo] continua neste ritmo, capítulos afora e presenteia o leitor com uma Maria muito mais exuberante, ultrapassando tanto a alcunha da embaixatriz, quanto a da amante de Duchamp.” (Borba, 2012, p.293). Ou seja, participa, em pé de igualdade com os e as artistas que deram visibilidade artística ao século XX. 
As notas aqui apresentadas, juntando pequenas pontas de um iceberg que é a produção da literatura e da arte brasileiras realizada pelas mulheres, tentou singularizarse em Maria Martins, focando em suas obras ou em parte delas, atualmente muito conhecidas, bastante comentadas e lidas e que, por isso mesmo, escolhi re-visitar (visitar novamente), re-ler (ler novamente), prestando mais atenção, desta vez, em alguns lugares de equivocidade, seja em relação à própria artista, seja em relação a seu trabalho sobre um lugar denominado de Amazônia.

\section{Considerações finais}

Proponho, em primeiro lugar, em cena comparatista, um alargamento de campo da história e da teoria da literatura, incluindo o das artes e, em segunda operação, a inclusão das mulheres, já que estes são, e continuam sendo, apesar dos esforços, predominantemente masculinos. Por isso este ensaio dá ênfase ao resgate da atuação de Maria Martins, assinalando seu lugar no bloco das mães grandes e generosas que, antes de nós, romperam as barricadas da vigilância de pais patronos padrinhos.

A artista brasileira movimentou as artes e letras do seu tempo, e, de algum modo, em suas histórias pessoais e opções estéticas, enfrentou com galhardia os problemas e atendeu aos seus apelos, sendo atravessada por eles, o que se tornou determinante de seus caminhos e obras, visuais ou escritas. Nesse trajeto se cruzam passadismo e modernidade, conservadorismo e ousadia. Com isso, o fato de, hoje em dia, ocupar lugar de destaque em catálogos e antologias, em exposições, coleções, bibliotecas e pinacotecas, deve-se a projetos individuais resultantes de negociações, por vezes de tergiversações, desvios, táticas de esquiva e não poucas superações de preconceitos.

Por indiferença, percalços financeiros, sobreposições de tarefas ou simples despreocupação com a opinião alheia, os jogos estratégicos de luta e sobrevivência das mulheres raras - artistas, poetas, escritoras - que em minhas pesquisas denominei preciosas $^{9}$, vinculam-se mais à herança materna que paterna e se montam na figuração de

\footnotetext{
${ }^{9}$ O projeto Uma Dicção Preciosa: Uma leitura das Poéticas do Presente iniciou com um estágio pósdoutoral na Universidade de Lisboa, em 2014, envolvendo poetas brasileiras e portuguesas consideradas "do Presente", um tempo recortado das produções de mulheres que escreveram desde a década de 80 do século XX. Daí resultaram várias publicações, conferências e artigos e a formação de um grupo atuante, na UFRGS, envolvendo alunos de Graduação (IC) e de Pós-graduação. A Pesquisa ocupou-se de linhas de força teóricas que mesclam corpo-imagem-linguagem e da teoria feminista, como as de Judith Butler (2002), por exemplo, além das relações entre corpo e escrita, como as da poeta e teórica argentina Tamara Kamenszain (2000). Na esteira das reflexões a respeito do neobarroco latino-americano, explorou, em paralelo, as grafias de uma "língua menor", nos sentidos dados por Deleuze e Guattari (1977). Propõe-se a
} 
um indecidível derridiano, propondo, em suas materialidades discursivas e em suas próprias histórias de vida, mais enigmas que certezas, mais opacidades que transparências e mais indagações que respostas.

Comentar simplesmente que, como Maria Martins, algumas dessas mulheres se tornaram canônicas, reduziria demasiadamente seus esforços e simplificaria de forma capciosa, se não machista, a atuação desbravadora que tiveram. Por isso, a matéria é mais complexa e demanda uma aproximação enviesada, contando com algum apoio teórico que sustente o enfrentamento como aprendizagem, o desafio como erotismo.

Resgato, portanto, em torno da obra de Jacques Derrida, duas referências: a escritora Hélène Cixous, a quem ele dedicou uma conferência (2003), - posteriormente publicada na França (2003) e no Brasil $(2005)^{10}$ - e, mais que isso, a quem, inúmeras vezes, em textos e entrevistas, ele se referiu como aquela que indicou o caminho para a teoria da desconstrução, na forma do binômio fundador homem-mulher, dos estudos feministas da década de 1950. Saliento também a professora belga Ann Van Sevenant, que ousou retirar uma frase de um texto do filósofo e torná-la sua, figurando-a em título de artigo, no qual ela explora um modo de ver e ler característico das artes do presente.

Em A verdade em pintura (2001), o teórico franco argelino define, ao analisar os desenhos de dupla face do artista italiano Valério Adami, uma teoria do dis-junto. Ann Van Sevenant replica as reflexões derridianas, inserindo-as em uma discussão que envolve a concretude dos limites na obra de arte, tomando para si essa ideia, que vira o título de um dos seus artigos: "O disjunto feito obra". Cita, no corpo do trabalho, o trecho de Derrida que deu o mote do título:

Duplo encaixe, dupla medida, a mesma, todavia, um encaixe sobreposto ao outro [...]. Cada encaixe é uma dupla coluna que desliza ou estria sobre a outra.

investigar certo anacronismo preciosista contemporâneo e sua potência em escrituras, figurando em suplementaridade e dando a ver os movimentos da teoria e da crítica, também, em relação aos gêneros, seja o literário, seja o da poesia escrita por mulheres. A obra de Maria Martins, embora fuja do escopo temporal estabelecido, por situar-se num contexto de recepção atual, obviamente, vai circular por todas as referências apontadas.

${ }^{10}$ A conferência foi pronunciada na abertura do colóquio "Hélène Cixous: Gêneses, genealogias, gêneros", na Biblioteca Nacional da França em maio de 2003. No mesmo ano, o texto apresentado é publicado pelas Éditions Galilée, em Paris. No Brasil, a tradução deste estudo recebeu o título de Gêneses, genealogias, gêneros e o gênio (2005), com tradução de Eliane Lisboa, vem a público pela Ed. Sulina, de Porto Alegre. No ensaio "Morfosis I e I. O canto e o espelho nos limiares da festa" (2012), em parceria com Marta Martins (UFSC), exploro um pouco a relação Derrida-Cixous: "Encontros podem ser estranhamente complementares: encontrar-se outro, como afirma Derrida, nessa abordagem-homenagem, que vai ao encontro da amiga escritora e encontra, em antecipações, escolhas e gênero, ele mesmo, para além de um gênero e do geral, genérico: encontra a ambos nos jogos desconstruídos de letra e imagem." (BITTENCOURT, MARTINS, 2012, p.255). Não por acaso, este ensaio foi escrito a quatro mãos e apresentado num contexto de homenagem. 
Mas como sempre em Adami, o desarticulado, o dissociado, o deslocado se retém, capturado ao mesmo tempo em que exposto: o dis-junto (agora feito obra). (Sevenant, apud Derrida, 2001, p.82. Tradução minha.)

A hipótese, aqui, aproveitando esta leitura da leitura da leitura, é a de que Maria Martins, ao falar e dar a ver a Amazônia, está sempre a falar-se, e também a falar de uma e de outra, de uma com a outra, de uma em outra, em simbiose humano-animal, humanovegetal, humano-espacial. Retorno à conferência dedicada a Cixous, em versão escrita, de Derrida, para dar destaque a uma observação entre parênteses:

(e eu me arrisco a dizer elipticamente que uma genialidade consiste talvez sempre em se encontrar, não apenas encontrar a si mesmo, mas se encontrar, entre tantos acontecimentos, de modo quase aleatório aqui ou lá, em lugar do outro, como o outro no lugar do outro) (2005, p.12).

Os parênteses, por si, já ligam e separam os fios do discurso. Tomando-o, na concordância no feminino e transpondo parte da citação derridiana, entendo que o confronto-encontro da artista e da floresta, resultaria em movimento espelhado: em lugar da outra, como a outra no lugar da outra. Trata-se, talvez de uma Amazônia muito populosa, densa e pulsante, composta de dor e êxtase, de elementos não encaixáveis e de ordens diversas, em textos e formas igualmente concretos e imaginários, dis-juntos $e$ juntos, como o que se replica, metamorficamente, três anos depois da exposição citada:

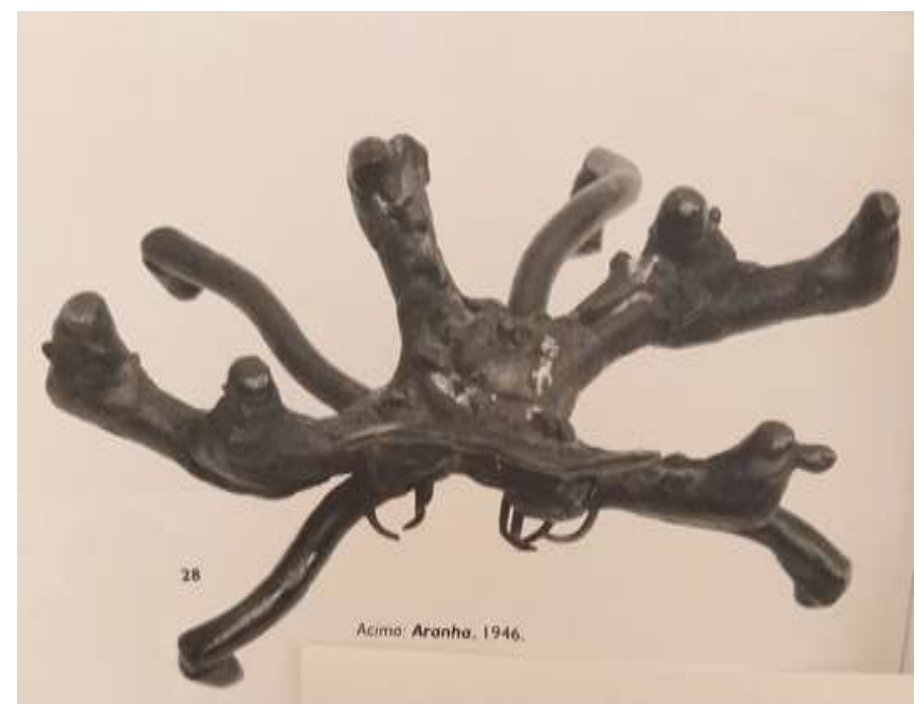

Fig. 3. Aranha, de 1946. Exposição dos Surrealistas, CCBB/RJ, 2001

Tão abstrata quanto fascinante, tão intempestiva quanto perigosa, a floresta é um imenso corpo de mulher, seja ela assassina ou amante. Também se conforma em serpente 
ou aranha, e, indistintamente, é o grande rio tortuoso, os riachos escondidos ou a anacrônica sereia, renomeada e diferida na Iara, que os habita. A produção da artista compartilha algo do que Derrida atribuiu a Cixous - a produção de uma obra como acontecimento:

\footnotetext{
a genialidade consiste necessariamente em fazer chegar, em dar lugar, em dar simplesmente, em dar nascimento à obra como acontecimento, rompendo paradoxalmente com qualquer genealogia, qualquer gênese e qualquer gênero. (2005, p.47).
}

Direcionado a uma ausência, lugar de impossibilidades topológicas - um Brasil sem Brasil; um Brasil no fora do Brasil, que de si mesmo é diverso - , Maria Martins explora, em sua poética da Amazônia, a potência do dis-junto, que, por sua vez, provoca desbordamentos da matéria em carne viva, ou bronze, ou madeira, ou letra.

\section{REFERÊNCIAS}

ANTELO, Raúl. Maria con Marcel: Duchamp en los trópicos. Buenos Aires: Siglo XXI, 2006.

Maria com Marcel: Duchamp nos trópicos. Belo Horizonte: UFMG, 2010.

BITTENCOURT, R. L. F. Guerra e Poesia. Dispositivos bélico-poéticos do modernismo. Porto Alegre: UFRGS, 2014.

. "Tensões Modernistas em Mário de Andrade, Tarsila do Amaral e Raul Bopp". In. VIS. Revista do Programa de Pós-graduação em Artes Visuais da UnB. V.18, número 2, 2019.

Disponível em: https://periodicos.unb.br/index.php/revistavis/issue/view/1956/396

ANTELO, Raúl; MARTINS, Marta. "Morfosis I e II. O canto e o espelho nos limiares da festa." In. SCRAMIM (Org.). O contemporâneo na Crítica Literária. São Paulo: Iluminuras, 2012.

BOPP, Raul. Seleta em prosa e verso. Rio de Janeiro: INL/MEC, 1975.

BORBA, Maria Salete. MARIA COM MARCEL, ou: releituras da modernidade periférica. Revista Organon, Núm.52. Porto Alegre: UFRGS, 2012. Resenha.

CALLADO, Ana Arruda. Maria Martins, uma biografia. Rio de Janeiro: Griphus; Brasília: Ministério da Cultura; Belo Horizonte: CEMIG, 2004.

COBRA Grande (imagem). In: ENCICLOPÉDIA Itaú Cultural de Arte e Cultura Brasileiras. São Paulo: Itaú Cultural, 2020. Verbete.

Disponível em: http://enciclopedia.itaucultural.org.br/obra14911/cobra-grande

Acesso em: 14 de Jun. 2020.

DERRIDA, Jacques. La verdad en pintura. Trad. María Cecília González y Dardo Scavino. Buenos Ares: Paidós, 2001.

2005 .

Gêneses, genealogias, gêneros e gênio. Trad. Eliane Lisboa. Porto Alegre: Sulina,

FABRIS, Annateresa (Org.). Modernidade e Modernismo no Brasil. Porto Alegre: Zouk, 2010. 
FREITAS, Angélica. Um útero é do tamanho de um punho. São Paulo: Cosac Naify, 2012.

GARRAMUÑO, Florência. Frutos estranhos: sobre a inespecificidade na estética contemporânea. Rio de Janeiro: Rocco, 2014.

GALVÃO, Walnice Nogueira. Modernismo. Roteiro da poesia brasileira. São Paulo: Global, 2008.

GOTLIB, Nádia Battella. Tarsila do Amaral, a modernista. São Paulo: SENAC, 2003.

KIFFER, Ana e GARRAMUÑO, Florência (Orgs.). Expansões Contemporâneas. Literatura e outras formas. Belo Horizonte: UFMG, 2014.

MARQUES, Ivan. Modernismo em Revista. Estética e ideologia nos periódicos dos anos 20. Rio de Janeiro: Casa da Palavra, 2013.

MATA, Larissa Costa da. "Da Amazônia, de Maria Martins". Revista Sibila (Cotia), v. 14, p. 1, 2013.

MINK, Janis. Marcel Duchamp 1887 - 1968. A arte como Contra-Arte. Trad. Zita Morais. Alemanha: Tashen, 2000.

SEVENANT, Ann Van. "Le disjoint fait oeuvre". In. ROELENS, Nathalie. Jacques Derrida et l'esthétique. Paris Montréal, l'Harmattan, 2000, pp. 71-85.

Recebido em 20/06/2020. Aceito em 29/07/2020. 